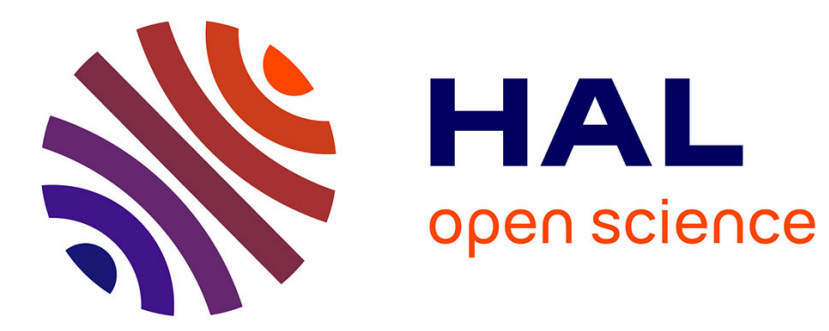

\title{
INELASTIC NEUTRON SCATTERING AND LATTICE DYNAMICS OF THE LAYER SEMICONDUCTOR GaS
}

\author{
A. Polian, K. Kunc, J. Rossat-Mignod
}

\section{> To cite this version:}

A. Polian, K. Kunc, J. Rossat-Mignod. INELASTIC NEUTRON SCATTERING AND LATTICE DYNAMICS OF THE LAYER SEMICONDUCTOR GaS. Journal de Physique Colloques, 1981, 42 (C6), pp.C6-295-C6-297. 10.1051/jphyscol:1981685 . jpa-00221621

\section{HAL Id: jpa-00221621 https://hal.science/jpa-00221621}

Submitted on 1 Jan 1981

HAL is a multi-disciplinary open access archive for the deposit and dissemination of scientific research documents, whether they are published or not. The documents may come from teaching and research institutions in France or abroad, or from public or private research centers.
L'archive ouverte pluridisciplinaire HAL, est destinée au dépôt et à la diffusion de documents scientifiques de niveau recherche, publiés ou non, émanant des établissements d'enseignement et de recherche français ou étrangers, des laboratoires publics ou privés. 


\title{
INELASTIC NEUTRON SCATTERING AND LATTICE DYNAMICS OF THE LAYER
} SEMICONDUCTOR GAS

\author{
A. Polian, K, Kunc and J, Rossat-Mignod \\ Laboratoire de Physique des Solides (Associẻ au C.N.R.S.), Université P. \& \\ M. Curie, 4, place Jussieu, F-75230 Paris Cedex 05, France \\ * DRF/DN, Centre d'Etudes Thucléaires, $85 \mathrm{X}$, F 38041 Grenoble Cedex, France
}

Abstract. - Measurements of the phonon dispersion curves of GaS in the $\Gamma \rightarrow M$ and $\bar{\Gamma} \rightarrow \mathrm{K} \rightarrow \mathrm{M}$ directions by inelastic neutron scattering have been performed. They show a non dispersive behaviour of the LA phonons in both directions. A Rigid Ion Model (RIM) with anisotropic effective charges and Axially Symetric Forces (ASF) is constructed from these data and discussed.

I. Experiment.- Inelastic neutron scattering experiments were performed on the layer crystal GaS on the IN3 and IN8 spectrometers at the ILI and DN1 at the C.E.N.G. Two experimental configurations were used allowing to obtain the phonon dispersion in the $\Gamma \rightarrow M$ and in the $\Gamma \rightarrow K \rightarrow M$ directions respectively. The experimental results shown in figure 1 match the earlier measurements $(1,2)$ and confirm the fact that, in the $\Gamma \rightarrow M$ direction, the LA mode is non-dispersive from $\vec{k} v(0.25,0,0)$ to the zone boundary. Similar features are found in the $\Gamma \rightarrow R$ direction and there is no dispersion between $M$ and $K$. The $B_{2}$ TA mode shows a similar behaviour.

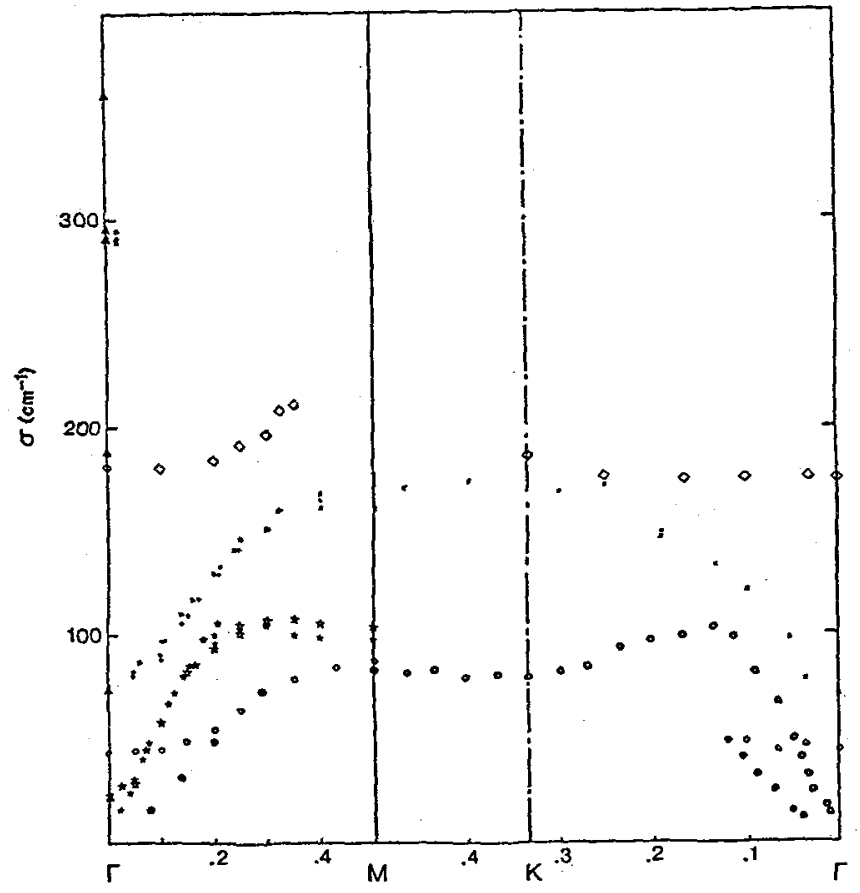

Fig. 1 : Experimental dispersion curves in the layer plane. Each symbol corresponds to a phonon with a different symetry. The phonons vibrating parallel to the $y$-axis are not shown here. 
The layered nature of the crystal is reflected in the quadratic dispersion at small wave vector of the out-of-the-layer-plane TA mode $\nu=\alpha \zeta+\beta \zeta^{2}$ : with frequency in $\mathrm{Hz}$ and reduced wave vector $\zeta=|\vec{k}| /\left|\vec{k}_{M}\right|, k_{M}=4 \pi / a \sqrt{3}$, our measurements yie1ded $\alpha=5 \times 10^{-12} \mathrm{~s}^{-1}$ and $\beta \simeq 10.5 \times 10^{-12} \mathrm{~s}^{-1}$. As $\beta / \alpha$ is zero in usual threedimensionnal crystals, and 10 in graphite, the present value of $\beta / \alpha=2$ indicates the degree of bidimensionnality.

2. Lattice Dynamics.- We used a Rigid Ion Model (RIM) associated with Axially Symetric Forces (ASF). The RIM is applied with an anisotropic effective charge tensor :

$$
z^{*}=\begin{array}{lll}
z_{1} & 0 & 0 \\
0 & z_{1} & 0 \\
0 & 0 & z_{2}
\end{array}
$$

in order to reproduce the anisotropy of the LO - TO splits at the zone center.

The set of 5 central forces ( 10 parameters $A_{i}, B_{i} ; i=1,5$ ) represents : interaction $n^{\circ} 1$ : Ga - Ga first neighbours; $n^{\circ} 2$ : Ga - S first neighbours; $n^{0} 3$ : $S-S$ interlayer; $n^{\circ} 4: G a-G a$ second neighbours (intralayer,intercell); $n^{\circ} 5$ : Ga - $\mathrm{S}$ second neighbours.

3. Discussion. - The ASF parameters $\mathrm{A}_{3}$ and $\mathrm{B}_{3}$ are calculated from the rigid layer modes $E_{2 g}\left(23 \mathrm{~cm}^{-1}\right)$ and $B_{2 g}\left(43 \mathrm{~cm}^{-1}\right)$, the other ones are obtained by least square fit to neutron data. The effective charges are obtained from Lo - To splits of the $\mathrm{E}_{1 \mathrm{u}}$ modes $\left(z_{1}=0.9 \mid \mathrm{e} /\right)$ and $\mathrm{A}_{2 \mathrm{u}}$ modes $\left(z_{2}=0.44 \mid \mathrm{e} /\right)$.

The dispersion curves calculated in the $\Gamma \rightarrow$ M direction are compared in figure 2. In spite of its simplicity, the model accounts well for all the zone center modes and provides elastic constants in good agreement with values obtained by Bxillouin scattering ${ }^{(3)}$. On the contrary, the non-dispersive behaviour of the LA phonons in the $\Gamma \rightarrow M$ direction could not be reproduced. While a flat region in the

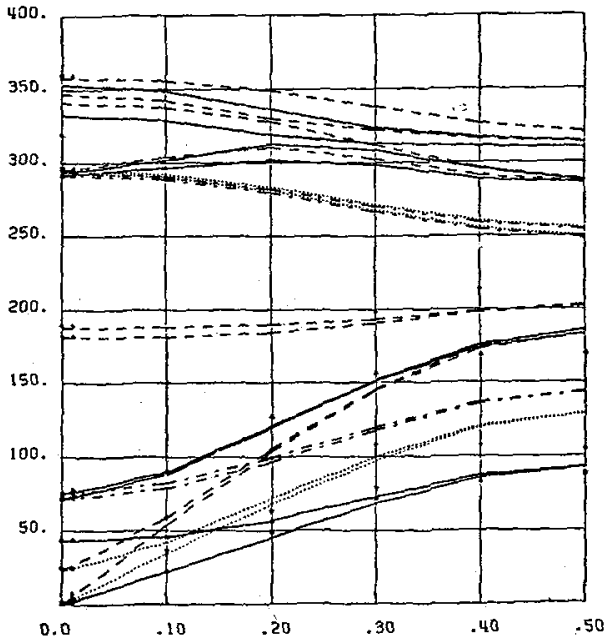
dispersion of TA modes was already observed in other materials like $\mathrm{Si}$ or Ge, a similar behaviour for the LA does not appear in other semiconducting materials.

A tentative explanation of this dispersion could be a coup 1 ing between the $A_{1}$ (LA)

Fig. 2 : Theoretical dispersion curves in the $\Gamma \rightarrow$ direction. - : $B_{1}$ modes;..$: B_{2}$ modes -- : $A_{1}^{1}$ modes; -:- : $A_{2}^{2}$ modes. 
mode and the $B_{1}\left(E_{1 g}\right.$ in $\Gamma$ ) mode.

Owing to the use of anisotropic effective charge, the present model is able to describe the angular dispersion of the zone center polar phonons. Due to the high symetry of GaS, the only experimental data available are those parallel and perpendicular to the c-axis so that the prediction cannot be checked. We prefered thus to show in figure 3 the dispersion predicted by the same model rather for $\gamma$-GaSe $\left(z_{1}=0.84|\mathrm{e}| ; z_{2}=0.39 \mid \mathrm{e} /\right)$ a closely related structure in which, however the different stacking and consequent1y lowered symetry made possible to obtain more complete data $(4,5)$.

Large polarisability of bonds in GaS, which is suggested by the space distribution of electronic charges $^{(6)}$ and shown by the high intensity of the Raman allowed lines raises some doubts about the adequacy of RTM for the description of the lattice dynamics of GaS. It is very likely that any of the standard dipole models (shell, d.d.m. etc.) would be

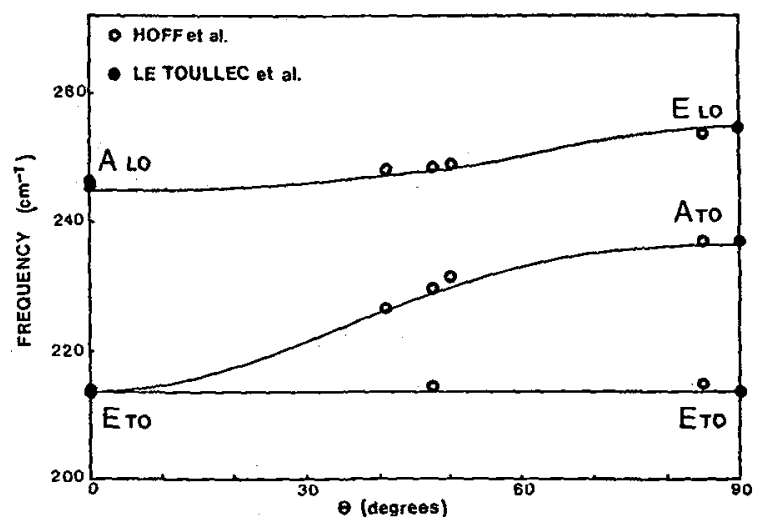
more satisfactory. It is questionable, however, whether the introduction of polarizable ions alone, would be sufficient to explain the non-dispersive behaviour of the $A_{1}$ (LA) and $B_{2}$ (TA) branches : looking for a description accounting explicitely for the large bond-charges showing up between the $\mathrm{Ga}$ atoms would probably be more appropriate.

\section{References}

(1) B.M. POWELL, S. JANDL, J.L. BREBNER and F. LEVY : J. Phys. C 10, 3039 (1977)

(2) A. POLIAN, K. KUNC, R. LETOULLEC and B. DORNER : Proc 14th I. C.P.S. Edinburgh 1978. Inst. Phys, Conf. Ser 43, 907 (1979)

(3) A. POLIAN, J.M. BESSON, M. GRTMSDITCH and H. VOGT : to be published, Phys. Rev.B

(4)R.M. HOFF, J.C. IRWIN and R.M.A. LIETH : Can. J. Phys. 53, 1606 (1974)

(5) R. LETOULLEC, N. PICCIOLI, M. MEJATTY and M. BALKANSKI : Nuevo Cimento $38 B$, 159 (1977)

(6) A. KUHN, A. BOURDON, J. RIGOULT and A. RIMSKY : submitted to Phys. Rev. 